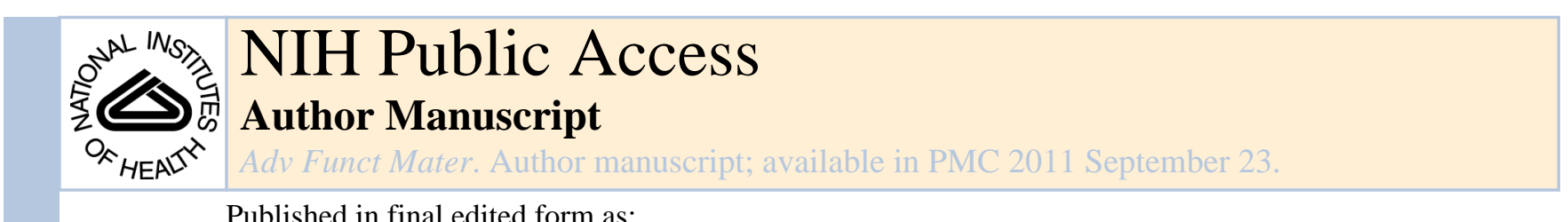

Published in final edited form as:

Adv Funct Mater. 2010 September 23; 20(18): 3005-3011. doi:10.1002/adfm.201000857.

\title{
Heterointegration of Pt/Si/Ag Nanowire Photodiodes and Their Photocatalytic Properties
}

\author{
Yongquan Qu, \\ Department of Chemistry and Biochemistry University of California, Los Angeles, CA 90095 \\ (USA) \\ Teng Xue, \\ Department of Materials Science and Engineering University of California, Los Angeles, CA \\ 90095 (USA)
}

\author{
Xing Zhong, \\ Department of Chemistry and Biochemistry University of California, Los Angeles, CA 90095 \\ (USA)
Yung-Chen Lin,
Department of Materials Science and Engineering University of California, Los Angeles, CA 90095 (USA)

Lei Liao,

Department of Chemistry and Biochemistry University of California, Los Angeles, CA 90095 (USA)

Jina Choi, and

W. M. Keck Laboratory California Institute of Technology, Pasadena, CA 91125 (USA)

Xiangfeng Duan*

Department of Chemistry and Biochemistry University of California, Los Angeles, CA 90095

(USA), California NanoSystems Institute University of California, Los Angeles, CA 90095 (USA)

Abstract

Photocatalyst mediated photoelectrochemical processes can make use of the photogenerated electrons and holes onsite for photocatalytic redox reactions, and enable the harness and conversion of solar energy into chemical energy, in analogy to natural photosynthesis. However, the photocatalysts available to date are limited by either poor efficiency in the visible light range or insufficient photoelectrochemical stability. We show that a Pt/Si/Ag nanowire heterostructure can be rationally synthesized to integrate a nanoscale metal-semiconductor Schottky diode encased in a protective insulating shell with two exposed metal catalysts. The synthesis of Pt/Si/ Ag nanowire diodes involves a scalable process including the formation of silicon nanowire array through wet chemical etching, electrodeposition of platinum and photoreduction of silver. We further demonstrated that the $\mathrm{Pt} / \mathrm{Si} / \mathrm{Ag}$ diodes exhibited highly efficient photocatalytic activity for a wide range of applications including environmental remediation and solar fuel production in the visible range. In this article, photodegradation of indigo carmine and 4-nitrophenol were used to evaluate the photoactivity of $\mathrm{Pt} / \mathrm{Si} / \mathrm{Ag}$ diodes. The $\mathrm{Pt} / \mathrm{Si} / \mathrm{Ag}$ diodes also show high activity for photoconversion of formic acid into carbon dioxide and hydrogen.

\footnotetext{
${ }^{\left[{ }^{*}\right]} \mathrm{Xduan} @$ chem.ucla.edu .
} 


\section{Keywords}

Nanowires; Heterostructures; Photodiodes; Photocatalysis

Exploring nanostructured materials for solar energy harvesting, conversion and storage has attracted considerable attention due to their significant potential to address the ever increasing challenges in renewable clean energy and environmental pollutions.[1-7] Inorganic nanostructures such as nanoparticles, nanowires, nanotubes and nanosheets have been widely investigated for applications in next-generation photovoltaic devices, in aiming at solar energy harvest and the conversion into electrical energy.[8-20] Alternatively, solar energy may also be harnessed, converted and stored as chemical energy using photocatalysts, in analogy to natural photosynthesis. For example, $\mathrm{TiO}_{2}$ nanostructures have been intensively studied as a promising photocatalyst due to its exceptional chemical and photochemical stability, and exhibit wide applications in the fields of clean energy and environmental remediation.[21-27] However, $\mathrm{TiO}_{2}$ nanomaterials are limited by their poor efficiency in the visible light range due to their large band gaps and limited absorption in visible spectrum.[26,27] Despite significant efforts to extend the absorption of $\mathrm{TiO}_{2}$ system towards longer wavelength, the photocatalytic efficiency of the $\mathrm{TiO}_{2}$ in visible light range still falls far from satisfactory.[23,28-39] Recently, II-VI and III-V compounds and some other ternary compounds such as $\mathrm{CuInX}_{2}(\mathrm{X}=\mathrm{S}, \mathrm{Se})$ have attracted great interest for solar energy harvesting because of their tunable band gap and strong absorption within visible light range.[40,41] However, such materials lack sufficient photoelectrochemical stability and are difficult to be implemented as photocatalysts due to significant photoelectrochemical degradation.[42,43]

We have recently reported a rational approach to design and integrate multiple functional components in a single nanowire heterostructure to obtain a new generation of highly efficient and stable photocatalysts.[44] Specifically, a nanoscale metal-semiconductor Schottky diode is encased in a protective insulating shell with two integrated metal catalysts in a heterojunction nanowire. The build-in potential within the Schottky diode promotes the rapid dissociation and transportation of the photoexcited electron-hole pairs which in turn improves the catalytic efficiency. The protective oxide shell also prevents direct electrochemical reaction on semiconductor surface and ensures exceptional photochemical stability of the system. However, the synthetic process of the reported nanowire heterostructures, involving colloid nanolithography, dry etching and electrodeposition, is rather complicated, time-consuming and expensive. Here we report a greatly simplified approach to synthesize hetero-integrated $\mathrm{Pt} / \mathrm{Si} / \mathrm{Ag}$ nanowire diodes, in which the silicon nanowire arrays are synthesized through a low-cost, one-step silver-assisted wet chemical etching method[45-47] and $\mathrm{Pt} / \mathrm{Si} / \mathrm{Ag}$ heterojunction nanowires are prepared through platinum electroplating [48] and self-catalyzed photoreduction of silver nitrate in bulk solution.[44] Photocatalytic studies show that the as-synthesized Pt/Si/Ag nanowire photocatalysts exhibit high activity and excellent stability when used for the photocatalytic degradation of organic dyes such as indigo carmine (IC) and toxic pollutants such as 4nitrophenol (4NP). The photocatalytic properties of the photodiodes are also evaluated by hydrogen generation process using formic acid as the sacrificial agent.

Figure 1a shows the schematic illustration of the working mechanism of the $\mathrm{Pt} / \mathrm{n}-\mathrm{Si} / \mathrm{Ag}$ nanowire diodes. Pt and n-Si forms a Schottky junction with a large built-in potential caused by the large work function difference between Pt and $\mathrm{n}-\mathrm{Si}(\sim 1.5 \mathrm{eV})$, while a smaller Schottky barrier is formed between $\mathrm{Ag}$ and $\mathrm{Si}$ with a much smaller work function difference $(\sim 0.2 \mathrm{eV})$. Under light irradiation, the electron-hole pairs generated near Pt/n-Si Schottky junction are quickly separated and migrate in opposite directions along the nanowires 
towards two separated metal catalysts at each end for the desired reduction and oxidation reactions.

The synthetic process for the $\mathrm{Pt} / \mathrm{n}-\mathrm{Si} / \mathrm{Ag}$ nanowire diodes is summarized in Figure 1b-1. Briefly, the n-type silicon nanowire arrays are obtained through a one-step silver-assisted electroless wet chemical etching process with an etchant solution containing $0.02 \mathrm{M} \mathrm{AgNO}_{3}$ and $5 \mathrm{M} \mathrm{HF}$ (Fig. 1b). The silicon nanowire arrays are then treated under ambient condition at $900{ }^{\circ} \mathrm{C}$ to form a $\sim 20 \mathrm{~nm}$ layer of silicon oxide as the protection layer (Fig. 1c). In order to form the $\mathrm{Pt} / \mathrm{Si}$ heterojunction, the nanowire array is completely covered with a layer of photoresist (AZ 5214) with the tips exposed by $\mathrm{O}_{2}$ plasma treatment. The silicon oxide layer of the exposed part of silicon nanowires is removed by oxide dry etching and the silicon nanowires are partially etched using $\mathrm{XeF}_{2}$ to yield the silicon nanowire/silicon oxide nanotube heterostructures (Fig. 1h). The sample is then immediately immersed into the platinum electroplating solution to deposit platinum into the nanoholes (Fig. 1i). Removal of photoresist leads to pure Pt/Si heterostructured nanowire arrays (Fig. 1j) and individual nanowires can be released into solvent by sonication (Fig. 1k). Lastly, Ag metal is deposited on the exposed silicon end through a self-catalyzed photoreduction process.

The microstructures of the silicon and Pt/Si nanowires were characterized by scanning electron microscopy (SEM) and transmission electron microscopy (TEM) (Fig. 2). Wet chemical etching process produced vertically oriented silicon nanowires with a length of 14 $\mu \mathrm{m}$ (Fig. 2a). The diameters of the etched silicon nanowires have a wide distribution ranging from $50 \mathrm{~nm}$ to $300 \mathrm{~nm}$. A $\sim 20 \mathrm{~nm}$ thick layer of silicon oxide shell was formed on the nanowires after baking in air at $900{ }^{\circ} \mathrm{C}$ for 60 minutes (Fig. 2b). The cross section SEM image and TEM image of the silicon nanowires after $\mathrm{XeF}_{2}$ etching clearly shows solid nanowires with an empty nanotube section (Fig. 2c, d). The etched holes typically exhibit variable lengths, which might be attributed to: (1) the wide distribution of the silicon nanowire diameters leads to different etching environments for each single nanowire which could in turn affect the etching rate; (2) The silicon nanowires tend to form "bundles" because of the surface tension in the aqueous solution, and the tilt angles of the silicon nanowires to the silicon substrate are slightly different for each nanowire. Therefore, the local $\mathrm{XeF}_{2}$ concentration is slightly varied for each silicon nanowire. The cross section SEM image of the etched silicon nanowire arrays after platinum electroplating does not show clear interface between platinum and silicon (Fig. 2e). Nonethelss, TEM image clearly shows silicon/platinum heterostructures interface (Fig. 2f). Extensive TEM studies indicate that over 80 percent of the silicon nanowires were filled with platinum metal in the nanoholes to obtain Pt/Si heterojunctions. High resolution TEM (HRTEM) and selected area electron diffraction (SAED) pattern show the typical polycrystalline nature of electrodeposited platinum (see Supporting Information, Fig. S1).

The vertical Pt/Si nanowire diodes are released from the silicon substrate and dispersed in aqueous solution through a sonication process. To prevent the formation of native oxide on the broken silicon end that could block electron transfer in the photoelectrochemical process, we have used a self-catalyzed photoreduction process to deposit another metal on the exposed silicon end. Within the Pt/Si photodiodes, the built-in potential ensures that the photogenerated electrons are always transported to silicon end for the reduction reaction (e.g. reduction of $\mathrm{Ag}^{+}$into $\mathrm{Ag}$ ). The reduced silver metal can protect the silicon from direct exposure to electrochemical reaction and oxidation degradation, as well as serve as the catalysts for the desired reduction reactions.

The reduction of silver ions was carried out by immediately dispersing fresh $\mathrm{Pt} / \mathrm{Si}$ nanowires in $1 \mathrm{mM}$ silver nitrate aqueous solution under light irradiation. The wavelength of the light was cut off at $532 \mathrm{~nm}$ in order to avoid significant homogeneous photodecomposition of 
silver nitrate. The temperature of the photoreduction reaction was kept below $35^{\circ} \mathrm{C}$ by air cool. This process is illustrated as follows:

$$
\begin{aligned}
& \text { Pt/Si nanowire photodiode } \stackrel{h v}{\longrightarrow} \mathrm{h}^{+}+\mathrm{e}^{-} \\
& \text {Cathode (silicon) }: \mathrm{Ag}^{+}+\mathrm{e}^{-} \rightarrow \mathrm{Ag} \quad \mathrm{E}_{0}=0.79 \mathrm{~V} \\
& \text { Anode (platinum) }: 2 \mathrm{H}_{2} \mathrm{O}+4 \mathrm{~h}^{+} \rightarrow \mathrm{O}_{2}+4 \mathrm{H}^{+} \mathrm{E}_{0}=-1.23 \mathrm{~V}
\end{aligned}
$$

The redox potential of the overall reaction is $-0.21 \mathrm{~V}$, calculated from the equation $\Delta E=\Delta E_{0}-0.05916 \log \frac{\left[\mathrm{H}^{+}\right]\left(\mathrm{a}_{\mathrm{O}_{2}}\right)^{0.25}}{\left[\mathrm{Ag}^{+}\right]}$, when the silver nitrate concentration is set at $1 \mathrm{mM}$ with a solution $\mathrm{pH}$ of 6.75 . The required potential is less than the open circuit voltage observed in the Pt/Si photodiodes as reported in our previous work, and the reaction can therefore effectively proceed forward. TEM image of a well-defined heterostructured nanowire photodiode clearly shows the formation of $\mathrm{Pt} / \mathrm{Si} / \mathrm{Ag}$ heterostructures nanowires (Fig. 3a). Energy-dispersive X-ray (EDX) spectra further confirm the three distinct sections in the heterojunction nanowires (Fig. 3 b-d).

With the photodeposition of silver on the exposed silicon end, we obtain a complete Pt/n-Si/ $\mathrm{Ag}$ heterojunction device in a single nanowire. The Pt/n-Si forms a Schottky diodes with significant built-in potential due to large work function difference $(\sim 1.5 \mathrm{eV})$. A much less significant Schottky barrier also exists at $\mathrm{Ag} / \mathrm{n}$-Si interface because of their small work function difference $(\sim 0.2 \mathrm{eV})$. Therefore, this heterostructure nanowire can work as a standalone photoelectric nanodevice for applications in photocatalysis. Under light irradiation, the electron-hole pairs can be generated and quickly separated by the built-in potential and transport in two opposite directions, with the electrons towards silver and holes towards platinum end. Thus, the photogenerated electrons and holes can be efficiently used for redox reaction on silver and platinum catalysts, enabling $\mathrm{Pt} / \mathrm{n}-\mathrm{Si} / \mathrm{Ag}$ heterojunction nanowires to function as highly efficient photocatalysts for a wide range of photocatalytic reactions.

The photocatalytic degradation of organic dyes or toxic pollutants is of great significance in environmental waste treatment, and represents an important way to characterize photocatalyst activity. To this end, two reactions were performed to evaluate the photocatalytic activity of the $\mathrm{Pt} / \mathrm{n}-\mathrm{Si} / \mathrm{Ag}$ nanowire photodiodes: photodegradation of organic dye IC and toxic pollutant 4NP. Upon the separation of photogenerated electron-hole pairs, the electrons and holes can be captured by water and the electrons by oxygen to produce reactive oxygen species (ROS), such as hydroxyl radicals $\left(\mathrm{OH}^{*}\right)$, superoxide $\left(\mathrm{O}_{2}{ }^{--}\right)$, singlet oxygen $\left({ }^{1} \mathrm{O}_{2}\right)$, and peroxide $\left(\mathrm{H}_{2} \mathrm{O}_{2}\right)$ that can act as strong oxidants.[49] The ROS are known as nonselective oxidizing agents for many organic pollutants. They can oxidize IC into $\mathrm{CO}_{2}$, $\mathrm{H}_{2} \mathrm{O}, \mathrm{HNO}_{3}$ and sodium sulfate. The reactions are listed as follows.

$$
\begin{aligned}
& \mathrm{Pt} / \mathrm{Si} / \mathrm{Ag} \text { nanowire photodiode } \stackrel{h v}{\rightarrow} \mathrm{h}^{+}+\mathrm{e}^{-} \\
& \text {Cathode: } \mathrm{O}_{2}+\mathrm{e}^{-} \rightarrow \mathrm{O}_{2}^{\bullet-} \\
& \text { Anode: } \mathrm{H}_{2} \mathrm{O}+\mathrm{h}^{+} \rightarrow \mathrm{OH}^{\bullet}+\mathrm{H}^{+} \\
& \text {ROS+indigo carmine } \rightarrow \text { intermediates } \rightarrow \mathrm{CO}_{2}+\mathrm{H}_{2} \mathrm{O}+\mathrm{HNO}_{3} \text { +sodium sulfate }
\end{aligned}
$$

To study the photodegradation behavior of the $\mathrm{Pt} / \mathrm{Si} / \mathrm{Ag}$ nanowires, approximately $2 \times 10^{9}$ of such photodiodes were dispersed in $10 \mathrm{ml}$ of $0.5 \mathrm{mM}$ of IC aqueous solution. The mixture was exposed to light irradiation from a $300 \mathrm{~W}$ xenon light under strong stirring. The reaction system was cooled by air flow. Small aliquots were taken out at different reaction time. The 
nanowire photodiodes were centrifuged off and the concentration of the IC aqueous solution was monitored by UV-vis absorption. Figure 4a shows the concentration of the IC solution as a function of reaction time. About $16.1 \%$ of IC molecules were degraded in the first 15 minutes with the aid of the Pt/n-Si/Ag nanowire photodiodes. In contrast, only $0.3 \%$ of IC molecules were degraded in the control reaction without the nanowire photodiodes. The apparent quantum efficiency $(\mathrm{QE})$ of the photodegradation was estimated to be $0.58 \%$ for the first 15 minutes assuming the IC molecules were completely degraded into $\mathrm{CO}_{2}, \mathrm{H}_{2} \mathrm{O}$, $\mathrm{HNO}_{3}$ and sodium sulfate. Previous studies suggested that the QE could be greatly affected by the initial IC concentration.[44,50] Higher concentration of the IC aqueous solution will increase the possibility for ROS species to be captured by the IC molecules. Similar experiment was carried out with identical amount of $\mathrm{Pt} / \mathrm{n}-\mathrm{Si} / \mathrm{Ag}$ nanowire photodiodes dispersed in $2 \mathrm{ml}$ of $10 \mathrm{mM}$ of IC aqueous solution for 1 minute of light irradiation. $1.9 \%$ of IC molecules were degraded to yield an apprent QE of $4.1 \%$, which is lower than that of the $\mathrm{Pt} / \mathrm{n}-\mathrm{Si} / \mathrm{n}^{+}-\mathrm{Si} / \mathrm{Ag}$ nanowire photodiodes we reported recently. This difference might be attributed to the small Schottky barrier between lightly doped silicon and silver, which may lower the efficiency of the electron transportation to silver catalysts compared to the Ohmic contact between highly doped silicon and silver in $\mathrm{Pt} / \mathrm{n}-\mathrm{Si} / \mathrm{n}^{+}-\mathrm{Si} / \mathrm{Ag}$ nanowire photodiodes. [44] After 210 minute of light irradiation, percentages of degraded IC molecules are $90.8 \%$ and $9.5 \%$ for reactions with and without $\mathrm{Pt} / \mathrm{n}-\mathrm{Si} / \mathrm{Ag}$ nanowire photodiodes, respectively. The results clearly demonstrate that the $\mathrm{Pt} / \mathrm{n}-\mathrm{Si} / \mathrm{Ag}$ nanowire photodiodes can act as effective photocatalysts to greatly accelerate the degradation of the organic dyes.

It is also important to evaluate the catalytic stability of the $\mathrm{Pt} / \mathrm{n}-\mathrm{Si} / \mathrm{Ag}$ nanowire photodiodes. Approximately $2.0 \times 10^{7} \mathrm{Pt} / \mathrm{n}-\mathrm{Si} / \mathrm{Ag}$ nanowire photodiodes were dispersed in $2 \mathrm{ml}$ of $10 \mu \mathrm{M}$ IC aqueous solution. The photodegradation reaction was carried out under natural sunlight irradiation (Los Angeles local time: 10:00 am to 6:00 pm) with strong stirring. The nanowire photodiodes were collected by centrifugation. The supernatant appears clear after the reaction and was collected for UV-vis absorption measurements to determine the concentration of IC in the aqueous solution. The recycled nanowire photodiodes were then redispersed in $2 \mathrm{ml}$ of $10 \mu \mathrm{M}$ fresh IC aqueous solution for another cycle of testing. The performance of the nanowire photodiodes is shown in Figure $4 \mathrm{~b}$. The Pt/n-Si/Ag nanowire photodiodes show stable catalytic behavior over the 30 days of the testing period. The fluctuation of the degraded percentage of IC does not exhibit a certain trend and is attributed to the variation of local weather.

Small aromatic molecules are hazardous environmental pollutant, and can be completely degraded into $\mathrm{CO}_{2}, \mathrm{H}_{2} \mathrm{O}$ and other small inorganic molecules under sunlight irradiation with appropriate photocatalysts. For the photocatalytic degradation of $4 \mathrm{NP}, 8 \times 10^{8}$ of Pt/n-Si/Ag nanowire photodiodes were dispersed in $10 \mathrm{ml}$ of $0.25 \mathrm{mM} 4 \mathrm{NP}$ aqueous solution. The photocatalytic performance of the nanowire diodes was shown in Figure 4c. At the end of the first 15 minutes of light irradiation, $10.3 \%$ of 4NP molecules were degraded in the reaction containing the $\mathrm{Pt} / \mathrm{Si} / \mathrm{Ag}$ nanowire photodiodes. In contrast, only $1.7 \%$ of $4 \mathrm{NP}$ molecules were degraded within the same period of time for the reaction without the nanowire photodiodes. The $4 \mathrm{NP}$ molecules were completely degraded by the $\mathrm{Pt} / \mathrm{Si} / \mathrm{Ag}$ nanowire photodiodes after 660 minutes of light irradiation. By comparison, only $29.7 \%$ of 4NP molecules were degraded without the nanowire photodiodes within this period of time.

Hydrogen has attracted increasing attention as an important renewable and environmental friendly energy source. Currently, steam reforming of methane or alcohol and water-gasshift reaction at high temperature are the major industrial methods to produce hydrogen. Formic acid, a nontoxic, cheap liquid at room temperature with a density of $1.22 \mathrm{~g} \mathrm{~cm}^{-3}$, has been explored as a hydrogen source due to its low flammability and high transportability. [51-53] Formic acid can undergo direct decomposition into $\mathrm{H}_{2}$ and $\mathrm{CO}_{2}$ without the 
formation of any other stable intermediates.[54] In this work, we have also explored $\mathrm{Pt} / \mathrm{Si}$ / $\mathrm{Ag}$ nanowires as photocatalyst to assist hydrogen production from formic acid. $3 \times 10^{9}$ photodiodes were well dispersed in $20 \mathrm{ml}$ of $2.7 \mathrm{M}$ formic acid aqueous solution. The result for this reaction is shown in Figure 4d. The photocatalytic behavior of the photodiodes showed an initial activation stage followed by a stable hydrogen production rate at $2.64 \times$ $10^{-4} \mu \mathrm{mol} \mathrm{s}^{-1}$. The apparent quantum yield $(\eta)$ for the hydrogen production can be determined by the following equation: $\varphi=\frac{2 \times \frac{d n_{H_{2}}}{d t}}{I_{O}}$, where $\frac{d n_{H_{2}}}{d_{1} t}$ is the hydrogen production rate $\left(\mathrm{mol} \mathrm{s}^{-1}\right)$ and Io is photon absorption rate in Einstein $\mathrm{s}^{-1}\left(\operatorname{mol}\left(\mathrm{e}^{-1}\right) \mathrm{s}^{-1}\right)$. The measured photon flux through the cell is $2.3 \times 10^{17}$ photons s$^{-1}$ and the calculated apparent average external quantum yield throughout the visible range for the $\mathrm{Pt} / \mathrm{Si} / \mathrm{Ag}$ photodiodes is $0.14 \%$. It should be noted that amount of light scattered by the photodiodes was not considered in the calculations and the actual internal quantum yield may be significantly higher.

In conclusion, the Pt/Si nanowire heterostructure were synthesized through a combination of silver-assisted electroless wet chemical etching and platinum electrodeposition, to form metal-semiconductor Schottky photodiodes. Silver was deposited on the silicon end of the $\mathrm{Pt} / \mathrm{Si}$ nanowires through a self-catalyzed photoreduction process to prevent oxidation of the exposed silicon and act as a catalyst for the desired reduction reactions. The $\mathrm{Pt} / \mathrm{Si} / \mathrm{Ag}$ heterojunction nanowire photodiodes are shown to function as standalone photoelectrochemical cells with exceptional photocatalytic properties for the photodegradation of organic dyes and toxic pollutants, or the generation of hydrogen from formic acid.

\section{Experimental}

\section{Synthesis of Silicon Nanowires}

Silicon nanowire arrays were synthesized through a one-step process involving electroless silver-assisted wet chemical etching. Briefly, pieces of the commercially available n-type $\mathrm{Si}$ (100) wafers with a resistivity of $0.3-0.8 \Omega \cdot \mathrm{cm}$ were used as starting materials. They were cleaned by sonicating in acetone and isopropanol and then dried by nitrogen flow. The cleaned silicon pieces were immersed into an etchant solution containing $0.02 \mathrm{M} \mathrm{AgNO}_{3}$ and 5.0 M HF for 60 minutes at room temperature. The $\mathrm{Ag}$ metal was removed from the nanowires by soaking the samples in concentrated nitric acid for at least one hour. Finally, the nanowires were thoroughly cleaned and baked under ambient conditions at $900{ }^{\circ} \mathrm{C}$ for 60 minutes to form a $\sim 20 \mathrm{~nm}$ silicon oxide shell on the nanowire surface.

\section{Formation of Pt/Si Nanowire Diodes}

$\mathrm{Pt} / \mathrm{Si}$ heterojunctions are formed by first drilling nanoholes at the top end of the etched $\mathrm{Si}$ nanowires followed by Pt electrodeposition inside the nanoholes. During the silicon oxide shell growth process, the tips of the Si nanowires were also oxidized. In order to drill nanoholes at the top end of the nanowires, the oxidized silicon oxide tips need to be selectively removed. A layer of photoresist AZ5214 was spun coated onto the Si nanowire substrate in order to fill the spaces between the nanowires and to cover the Si nanowires completely. Oxygen plasma was then employed to partially remove the photoresist to expose the tips of the nanowires. The silicon oxide tips were then etched away by a mixture of CHF3 and Ar gas in Oxford Plasmalab 80 plus. The silicon oxide sidewalls of the nanowires and the bottom silicon oxide on the substrates were protected by the photoresist. In order to remove the $\mathrm{Si}$ core to yield the nanoholes, the Si nanowire arrays were immediately transferred into the $\mathrm{XeF}_{2}$ etching chamber. Pressure of the $\mathrm{XeF}_{2}$ was kept at 0.5 torr and the depths of the nanoholes were controlled by tuning the etching time. After the formation of 
the nanoholes, the Si nanowires were immediately immersed into a platinum electroplating solution containing $5 \mathrm{mM} \mathrm{H}_{2} \mathrm{PtCl}_{6}$ and $2 \mathrm{mM} \mathrm{HCl}$ to fill the nanoholes with Pt. The electroplating was carried out under constant current density of $0.2 \mathrm{~mA} / \mathrm{cm}^{2}$. The Ptdeposited samples were washed several times with hot acetone to remove photoresist and cleaned by $\mathrm{O}_{2}$ plasma to remove any remaining residue.

\section{Synthesis of Pt/n-Si/Ag Nanowire Diodes}

In order to prevent the formation of a native silicon oxide layer at the end of the $\mathrm{Si}$ nanowires, which may block electron transfer in photocatalytic reactions, silver metal was deposited on the Si nanowires thourgh a self-catalyzed photoreduction process. Clean $\mathrm{Pt} / \mathrm{Si}$ nanowire arrays were released into $1 \mathrm{mM} \mathrm{AgNO}{ }_{3}$ solution by sonication. The solution containing the nanowires was immediately exposed to simulated sunlight from a $300 \mathrm{~W}$ Xenon light. The wavelength of the light was cut off at $532 \mathrm{~nm}$ to avoid significant photodecomposition of silver nitrate. The resulted nanostructures were collected by centrifugation followed by washing with deionized water for three times.

\section{Photocatalytic Properties of Pt/n-Si/Ag Nanowire Heterostructures}

For the photodegradation of indigo carmine (IC), a $10 \mathrm{ml}$ of $0.5 \mathrm{mM}$ IC aqueous solution mixed with $2 \times 10^{9} \mathrm{Pt} / \mathrm{Si} / \mathrm{Ag}$ nanowire photodiodes and the mixture was exposed to a $300 \mathrm{~W}$ Xe lamp. The concentration of IC was determined by the UV absorption of the dye at $\lambda_{\max }=$ $618 \mathrm{~nm}$. For the photocatalytic stability test, $2 \times 10^{7} \mathrm{Pt} / \mathrm{Si} / \mathrm{Ag}$ nanowire photodiodes dispersed in $2 \mathrm{ml}$ of $10 \mu \mathrm{M}$ IC dye aqueous solution was used for the IC photodegradation under natural sunlight from 10:00 am to 6:00 pm of Los Angeles local time. The catalysts were centrifuged off, washed with DI water for three times and re-dispersed in $2 \mathrm{ml}$ of fresh $10 \mu \mathrm{M}$ IC dye aqueous solution for a new cycle of test. Photodegradation of 4NP were carried out with $8 \times 10^{8} \mathrm{Pt} / \mathrm{Si} / \mathrm{Ag}$ photodiodes dispersed in $10 \mathrm{ml}$ of $0.25 \mathrm{mM} 4 \mathrm{NP}$ aqueous solution. The degradation was characterized by the ratio of the remaining $4 \mathrm{NP}$ concentration to its original concentration.

\section{Photocatalytic Hydrogen Production}

Photocatalytic reactions for hydrogen generation were carried out in an air-tight reactor under the visible light irradiation $(\lambda>400 \mathrm{~nm})$. Approximately $3 \times 10^{9} \mathrm{Pt} / \mathrm{Si} / \mathrm{Ag}$ photodiodes were dispersed in $20 \mathrm{ml}$ of $2.7 \mathrm{M}$ formic acid aqueous solution. The sample was purged with nitrogen gas for 60 minutes before light irradiation in order to remove the dissolved oxygen. A high pressure $500 \mathrm{~W} \mathrm{Hg}$-Xe arc lamp was used as the primary light source. The intensity of incident light was measured by ferroxalate actinometry to determine the quantum yields for the hydrogen generation. The amount of hydrogen was analyzed by gas chromatography (GC) / thermal conductivity detector (TCD) (HP5890, nitrogen carrier) with a molecular sieve column $(30 \mathrm{~m} \times 0.32 \mathrm{~mm} \times 12.0 \mu \mathrm{m})$.

\section{Characterization}

The as-grown samples were inspected by scanning electron microscope (SEM) (JEOL 6700) imaging at $10 \mathrm{keV}$ of electron acceleration voltage. Transmission electron microscope (TEM) imaging of the SiNWs was conducted on a Phillips CM120 with a $120 \mathrm{kV}$ operation voltage. The energy dispersive X-ray (EDX) spectroscopy, HRTEM and SAED were collected on FEI TITAN with a $300 \mathrm{kV}$ operation voltage.

\section{Supplementary Material}

Refer to Web version on PubMed Central for supplementary material. 


\section{Acknowledgments}

We acknowledge support by the NIH Director's New Innovator Award Program, part of the NIH Roadmap for Medical Research, through Grant 1DP2OD004342-01. We acknowledge Electron Imaging Center for Nanomachines (EICN) at UCLA for support for TEM, Nanoelectronics Research Facility at UCLA for support of etching process. We are grateful to Professor Michael R. Hoffmann for hydrogen quantification equipment.

\section{Reference}

[1]. Hagfeldt A, Gratzel M. Accounts of Chemical Research. 2000; 33:269. [PubMed: 10813871]

[2]. Gomez-Romero P. Advanced Materials. 2001; 13:163.

[3]. Nozik AJ. Physica E-Low-Dimensional Systems \& Nanostructures. 2002; 14:115.

[4]. Goetzberger A, Hebling C, Schock HW. Materials Science \& Engineering R-Reports. 2003; 40:1.

[5]. Lewis NS. Science. 2007; 315:798. [PubMed: 17289986]

[6]. Thompson BC, Frechet JMJ. Angewandte Chemie-International Edition. 2008; 47:58.

[7]. Tian B, Kempa TJ, Lieber CM. Chemical Society Reviews. 2009; 38:16. [PubMed: 19088961]

[8]. Law M, Greene LE, Johnson JC, Saykally R, Yang PD. Nature Materials. 2005; 4:455.

[9]. Gur I, Fromer NA, Geier ML, Alivisatos AP. Science. 2005; 310:462. [PubMed: 16239470]

[10]. Tian BZ, Zheng XL, Kempa TJ, Fang Y, Yu NF, Yu GH, Huang JL, Lieber CM. Nature. 2007; 449:885. [PubMed: 17943126]

[11]. Yang C, Barrelet CJ, Capasso F, Lieber CM. Nano Letters. 2006; 6:2929. [PubMed: 17163733]

[12]. Kelzenberg MD, Turner-Evans DB, Kayes BM, Filler MA, Putnam MC, Lewis NS, Atwater HA. Nano Letters. 2008; 8:710. [PubMed: 18269257]

[13]. Kempa TJ, Tian BZ, Kim DR, Hu JS, Zheng XL, Lieber CM. Nano Letters. 2008; 8:3456. [PubMed: 18763836]

[14]. Tada H, Mitsui T, Kiyonaga T, Akita T, Tanaka K. Nature Materials. 2006; 5:782.

[15]. Costi R, Saunders AE, Elmalem E, Salant A, Banin U. Nano Letters. 2008; 8:637. [PubMed: 18197720]

[16]. Dukovic G, Merkle MG, Nelson JH, Hughes SM, Alivisatos AP. Advanced Materials. 2008; 20:4306.

[17]. Menagen G, Macdonald JE, Shemesh Y, Popov I, Banin U. Journal of the American Chemical Society. 2009; 131:17406. [PubMed: 19894717]

[18]. Schierhorn M, Boettcher SW, Kraemer S, Stucky GD, Moskovits M. Nano Letters. 2009; 9:3262. [PubMed: 19705806]

[19]. Osterloh FE. Chemistry of Materials. 2008; 20:35.

[20]. Boettcher SW, Spurgeon JM, Putnam MC, Warren EL, Turner-Evans DB, Kelzenberg MD, Maiolo JR, Atwater HA, Lewis NS. Science. 2010; 327:185. [PubMed: 20056886]

[21]. Varghese OK, Grimes CA. Journal of Nanoscience and Nanotechnology. 2003; 3:277. [PubMed: 14598441]

[22]. Hoffmann MR, Martin ST, Choi WY, Bahnemann DW. Chemical Reviews. 1995; 95:69.

[23]. Asahi R, Morikawa T, Ohwaki T, Aoki K, Taga Y. Science. 2001; 293:269. [PubMed: 11452117]

[24]. Bisquert J, Cahen D, Hodes G, Ruhle S, Zaban A. Journal of Physical Chemistry B. 2004; 108:8106.

[25]. Frank AJ, Kopidakis N, van de Lagemaat J. Coordination Chemistry Reviews. 2004; 248:1165.

[26]. Kudo A, Miseki Y. Chemical Society Reviews. 2009; 38:253. [PubMed: 19088977]

[27]. Zhang HJ, Chen GH, Bahnemann DW. Journal of Materials Chemistry. 2009; 19:5089.

[28]. Li SX, Zheng FY, Liu XL, Wu F, Deng NS, Yang JH. Chemosphere. 2005; 61:589. [PubMed: 16202814]

[29]. Wang C, Li J, Mele G, Yang GM, Zhang FX, Palmisano L, Vasapollo G. Applied Catalysis BEnvironmental. 2007; 76:218.

[30]. Choi J, Park H, Hoffmann MR. Journal of Physical Chemistry C. 2010; 114:783. 
[31]. Rodrigues S, Ranjit KT, Uma S, Martyanov IN, Klabunde KJ. Advanced Materials. 2005; 17:2467.

[32]. Choi J, Park H, Hoffmann MR. Journal of Materials Research. 2010; 25:149.

[33]. Usseglio S, Damin A, Scarano D, Bordiga S, Zecchina A, Lamberti C. Journal of the American Chemical Society. 2007; 129:2822. [PubMed: 17305337]

[34]. Luo HM, Takata T, Lee YG, Zhao JF, Domen K, Yan YS. Chemistry of Materials. 2004; 16:846.

[35]. Ratanatawanate C, Tao Y, Balkus KJ. Journal of Physical Chemistry C. 2009; 113:10755.

[36]. Baker DR, Kamat PV. Advanced Functional Materials. 2009; 19:805.

[37]. Choi J, Park H, Hoffmann MR. Journal of Physical Chemistry C. 2010; 114:783.

[38]. Liu L, Henset J, Fitzmorris RC, Li Y, Zhang JZ. Journal of Physical Chemistry Letters. 2010; $1: 155$.

[39]. Hensel J, Wang GM, Li Y, Zhang JZ. Nano Letters. 10:478. [PubMed: 20102190]

[40]. Afzaal M, O’Brien P. Journal of Materials Chemistry. 2006; 16:1597.

[41]. Li Y, Qian F, Xiang J, Lieber CM. Materials Today. 2006; 9:18.

[42]. Manassen J, Cahen D, Hodes G, Sofer A. Nature. 1976; 263:97.

[43]. Tsubomura H, Matsumura M, Nakatani K, Yamamoto K, Maeda K. Solar Energy. 1978; 21:93.

[44]. Qu YQ, Liao L, Cheng R, Wang Y, Lin YC, Huang Y, Duan XD. Nano Letters. 2010 DOI: 10.1021/nl101010m.

[45]. Peng KQ, Yan YJ, Gao SP, Zhu J. Advanced Functional Materials. 2003; 13:127.

[46]. Peng KQ, Huang ZP, Zhu J. Advanced Materials. 2004; 16:73.

[47]. Qu YQ, Liao L, Li YJ, Zhang H, Huang Y, Duan XF. Nano Letters. 2009; 9:4539. [PubMed: 19807130]

[48]. Hu-Lin L, Guang-Yu Z, Cai-Ling X, Dao-Jun G, Hua L. Applied Surface Science. 2007; 253:3242.

[49]. Rajeshwar K, Osugi ME, Chanmanee W, Chenthamarakshan CR, Zanoni MVB, Kajitvichyanukul P, Krishnan-Ayer R. Journal of Photochemistry and Photobiology CPhotochemistry Reviews. 2008; 9:171.

[50]. Subramani AK, Byrappa K, Ananda S, Rai KML, Ranganathaiah C, Yoshimura M. Bulletin of Material Science. 2007; 30:37.

[51]. Jessop PG, Ikariya T, Noyori R. Chemical Reviews. 1995; 95:259.

[52]. Malla PB, Ravindranathan P, Komarneni S, Roy R. Nature. 1991; 351:555.

[53]. Hayashi H, Ogo S, Fukuzumi S. Chemical Communications. 2004:2714. [PubMed: 15568081]

[54]. Kakuta S, Abe T. Acs Applied Materials \& Interfaces. 2009; 1:2707. [PubMed: 20356147] 


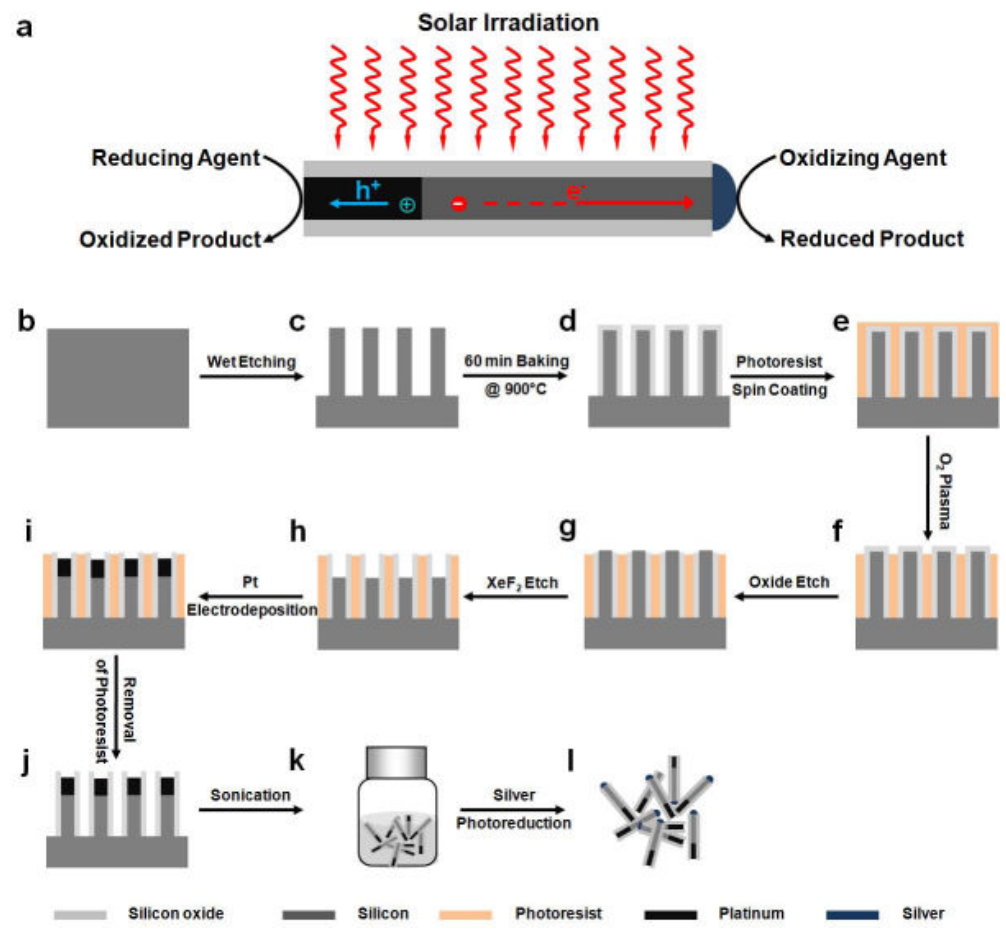

\section{Figure 1.}

Schematic illustration of the synthesis of $\mathrm{Pt} / \mathrm{Si} / \mathrm{Ag}$ nanowire heterostructures. (a) Schematic illustration of a metal-semiconductor-metal photoelectric nanodevice as a highly efficient photocatalyst. A Pt/n-Si/Ag heterostructure is created in a single nanowire to integrate a nanoscale metal-semiconductor Schottky photodiode ( $\mathrm{Pt}-\mathrm{Si})$ encased in a protective insulating shell with two exposed metal catalysts (Pt, Ag). (b) The starting lightly doped silicon wafer. (c) Formation of silicon nanowire arrays by silver-assisted electroless wet chemical etching. (d) Formation of silicon oxide shell on Si nanowires by baking the sample under ambient conditions at $900{ }^{\circ} \mathrm{C}$ for $60 \mathrm{~min}$. (e) Spin coating of photoresist AZ 5214 as a protecting layer for the substrate. (f) Exposure of the tips of the silicon nanowires through $\mathrm{O}_{2}$ plasma etching. (g) Exposure of the Si core of the silicon oxide-encased Si nanowires by oxide dry etching. (h) Drilling of the nanoholes in the Si nanowires by $\mathrm{XeF}_{2}$ dry etching. (i) Pt electrodeposition. (j) Removal of photoresist AZ 5214. (k) Release of Pt/Si nanowires into solvent through sonication. (l) Self-catalyzed photoreduction of silver by irradiation on freshly released $\mathrm{Pt} / \mathrm{Si}$ nanowires in $\mathrm{AgNO}_{3}$ aqueous solution. 

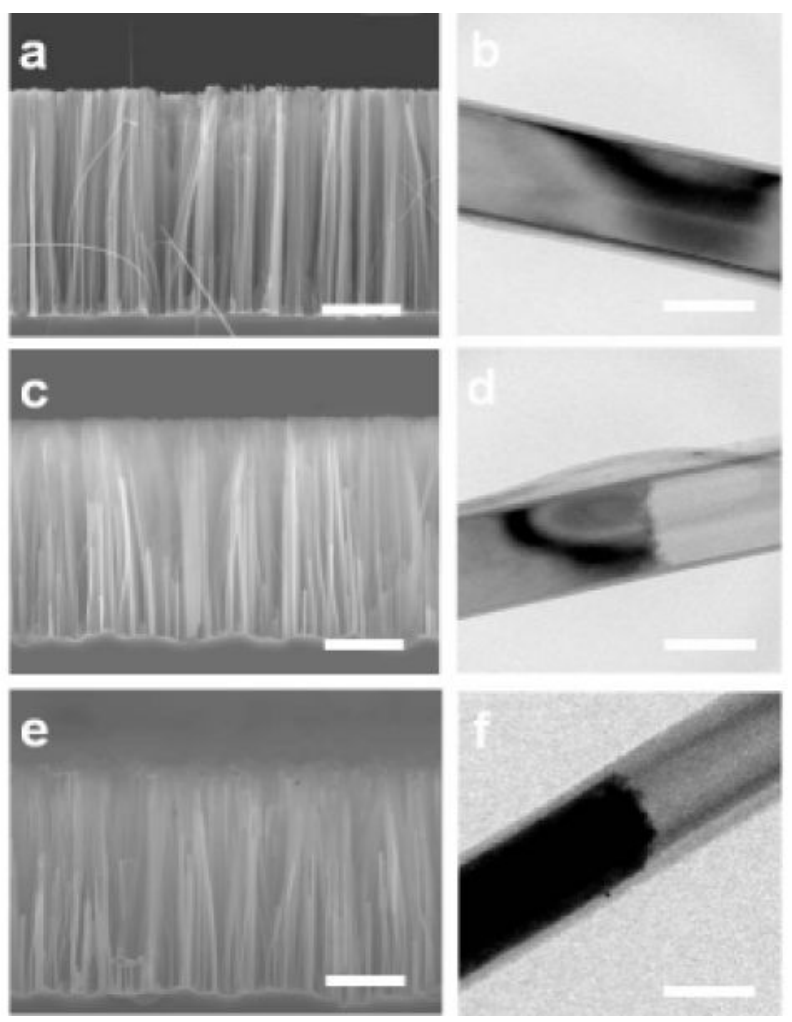

Figure 2.

Structural characterization of the nanowire heterostructures. (a) SEM image of a crosssectional view of the silicon nanowire array after $900{ }^{\circ} \mathrm{C}$ baking under ambient conditions. (b) TEM image of a wet etched silicon nanowire after $900{ }^{\circ} \mathrm{C}$ baking. (c) SEM image of a cross-sectional view of the silicon nanowire array with nanoholes. (d) TEM image of a silicon nanowire with a nanohole. (e) SEM image of a cross-sectional view of the $\mathrm{Pt} / \mathrm{Si}$ nanowire array. (f) TEM image of a Pt/Si nanowire heterojunction. Scale bar is $5 \mu \mathrm{m}$ for a, $\mathrm{c}$, and $\mathrm{e}$ and $200 \mathrm{~nm}$ for $\mathrm{b}, \mathrm{d}$ and $\mathrm{f}$. 
a
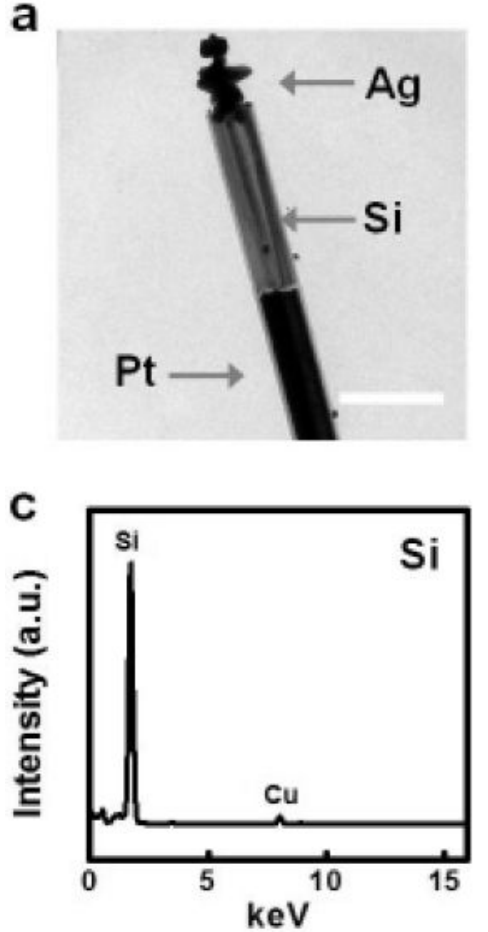

b
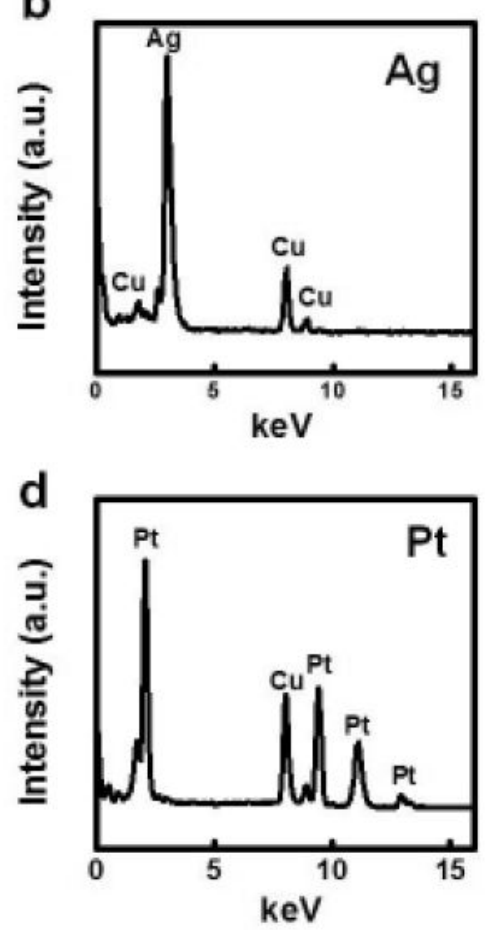

Figure 3.

Structural and compositional characterization of the $\mathrm{Pt} / \mathrm{Si} / \mathrm{Ag}$ nanowire heterostructure. (a) TEM image of a Pt/Si/Ag nanowire heterostructure. The scale bar is $600 \mathrm{~nm}$. (b-d) EDX spectra of three distinct sections of the $\mathrm{Pt} / \mathrm{Si} / \mathrm{Ag}$ nanowire heterostrcture. 

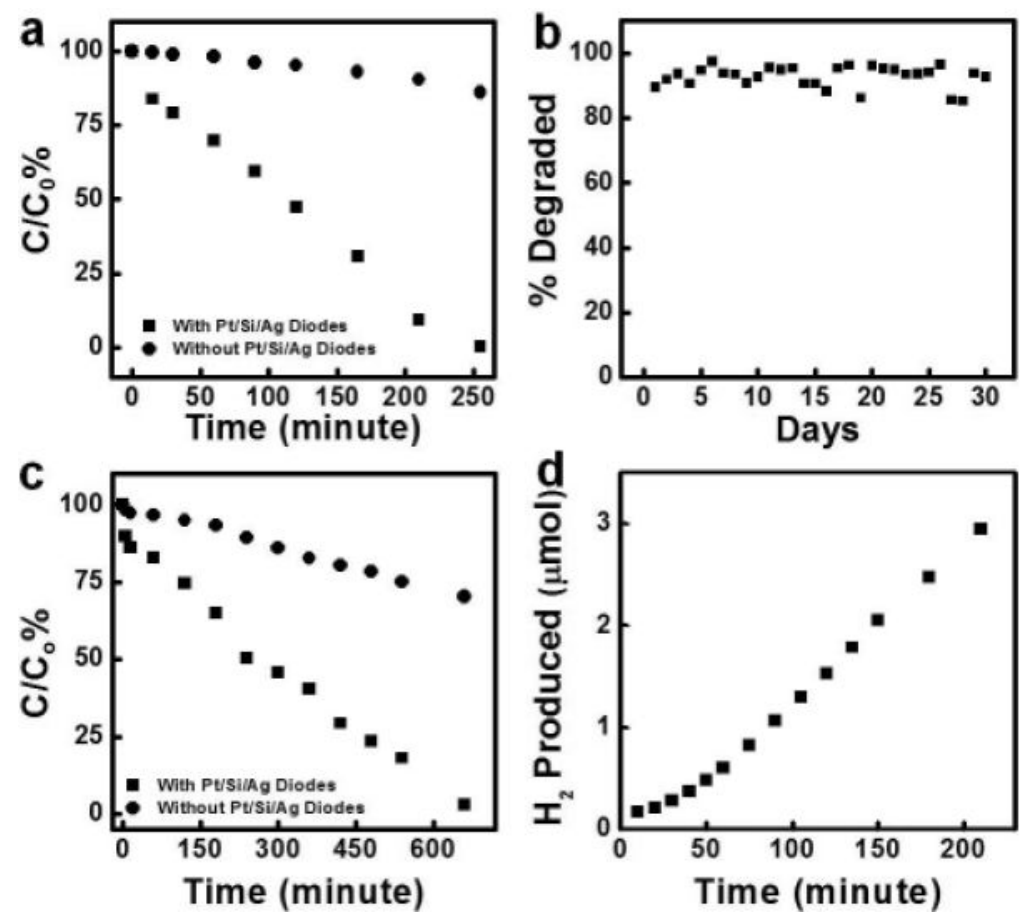

Figure 4.

Photocatalytic properties of $\mathrm{Pt} / \mathrm{Si} / \mathrm{Ag}$ heterostructure photodiodes. (a) Photocatalytic degradation of indigo carmine (IC) with $2 \times 10^{9} \mathrm{Pt} / \mathrm{Si} / \mathrm{Ag}$ photodiodes dispersed in $10 \mathrm{ml}$ of $0.5 \mathrm{mM}$ IC aqueous solution. The degradation was characterized by the ratio of the remaining IC concentration to its original concentration. The circles represent the photodegradation reaction of IC without photodiodes. The squares represent the same photodegradation reaction of IC with photodiodes. (b) Photocatalytic stability of the $\mathrm{Pt} / \mathrm{Si} /$ Ag photodiodes in the IC degradation reaction. The experiment is carried out with $2.0 \times 10^{7}$ diodes dispersed in $2 \mathrm{ml}$ of $10 \mu \mathrm{M}$ IC aqueous solution under natural sunlight irradiation during Los Angeles local time from 10:00 am to 6:00 pm. (c) Photodegradation of 4NP with $8 \times 10^{8} \mathrm{Pt} / \mathrm{Si} / \mathrm{Ag}$ photodiodes dispersed in $10 \mathrm{ml}$ of $0.25 \mathrm{mM} 4 \mathrm{NP}$ aqueous solution. The degradation was characterized by the ratio of the remaining NP concentration to its original concentration. The circles represent the photodegradation reaction of 4NP without photodiodes. The squares represent the same photodegradation reaction of 4NP with photodiodes. (d) Hydrogen production based on oxidation of formic acid catalyzed by $\mathrm{Pt} / \mathrm{Si} /$ Ag photodiodes. 